\title{
Mudanças climáticas, riscos e adaptação na megacidade de São Paulo, Brasil ${ }^{1}$
}

\author{
Climate change, risks and adaptation \\ in the megacity of São Paulo, Brazil
}

Gabriela Marques Di Giulio ${ }^{a}$

Ana Maria Bedran-Martins ${ }^{b}$

Maria da Penha Vasconcellos ${ }^{c}$

Wagner Costa Ribeiro ${ }^{d}$

\begin{abstract}
'Docente do Departamento de Saúde Ambiental, Faculdade de Saúde Pública, Universidade de São Paulo, São Paulo, SP, Brasil End. Eletrônico: ggiulio@usp.br

${ }^{b}$ Doutora em Saúde Pública, Faculdade de Saúde Pública, Universidade de São Paulo, São Paulo, SP, Brasil End. Eletrônico: anabedran@usp.br

'Docente do Departamento de Saúde Ambiental, Faculdade de Saúde Pública, Universidade de São Paulo, São Paulo, SP, Brasil End. Eletrônico: mpvascon@usp.br

${ }^{d}$ Docente do Departamento de Geografia, Universidade de São Paulo São Paulo SP. Brasil End. Eletrônico: wribeiro@usp.br
\end{abstract}

doi:10.18472/SustDeb.v8n2.2017.19868

\section{RESUMO}

O artigo discute resultados de uma pesquisa sobre questões climáticas na megacidade de São Paulo. Dialogando com a literatura e tendo como base estudo realizado entre 2014 e 2015, reflete sobre o papel do poder local no processo de buscar sinergias entre adaptação, mitigação e desenvolvimento por meio da experimentação. Os autores discutem ações implementadas em São Paulo com potencial para responder aos desafios climáticos, com foco nas intervenções que não estão diretamente associadas ao discurso climático. Exemplos dessas intervenções são as propostas do Plano Diretor e ações de mobilidade urbana adotadas na gestão municipal (2013-2016). Esses projetos e a adoção de uma agenda socioambiental podem se constituir como respostas às mudanças climáticas, promovendo sinergias entre adaptação e mitigação. Os autores concluem o artigo sinalizando desafios para a adaptação na capital paulista, considerando suas especificidades e complexidades nos planos econômico/político/ social.

Palavras-chave: Mudanças Climáticas; Adaptação; Capacidade Adaptativa; Risco. Megacidade; São Paulo. 


\begin{abstract}
The paper debates findings of a research related to climate issues in the megacity of São Paulo. Based on literature review and on a empirical study conducted between 2014-2015, we shed light on the role of local political power in the process of seeking synergies amongst adaptation, mitigation and development through experimentation. We discuss local actions with potential to respond to climatic challenges, focusing on interventions that have not been directly associated to the climatic discourse. Examples of these interventions include the new Master Plan and urban mobility actions adopted by the municipal government (2013-2016). We argue that those strategies and the adoption of a socioenvironmental agenda may be concrete local responses to climate change, connecting synergies between adaptation and mitigation. We conclude exploring some barriers for local adaptation, considering the specificities and complexities in the economic, social and political spheres.
\end{abstract}

Keywords: Climate Change; Adaptation; Adaptive Capacity; Risk; Megacity; São Paulo.

\title{
1 INTRODUÇÃO
}

Densidade populacional, desigualdades, modernização de infraestrutura e logística urbana são desafios comuns a diversas megacidades no mundo. Alterar a lógica de desenvolvimento urbano nessas megacidades para enfrentar esses e futuros desafios passa pelo entendimento de que as ações colocadas em prática precisam estar articuladas ao debate atual sobre mudanças climáticas, compreendendo, particularmente, que é na esfera local que as populações são afetadas de forma direta e que as ações de ajustamentos e adaptação precisam ser pensadas e implantadas com urgência (AMBRIZZI et al., 2012; HOGAN, 2007; KASPERSON et al., 2005; RIBEIRO, 2008).

Filiado ao debate interdisciplinar sobre cidades, mudanças climáticas e sustentabilidade, este artigo traz resultados de uma pesquisa que investigou a experiência em curso da megacidade de São Paulo relacionada às questões climáticas e ao conjunto de novos riscos e possíveis ameaças que podem agravar as situações adversas já presentes para sua população.

Como marcos teóricos adotados, destaca-se a ideia de cidade "enquanto construção humana; produto histórico-social, contexto no qual a cidade aparece como trabalho materializado, acumulado ao longo de uma série de gerações, a partir da relação da sociedade com a natureza" (CARLOS, 2004, p. 19). Em um contexto de globalização e de cosmopolitização, no qual as localidades internalizam o que é global (BECK, 2002), as cidades e os governos locais exercem um papel político revitalizado (GIDDENS, 2005). Nessa perspectiva, como argumenta Giddens (2005), os prefeitos das grandes cidades têm o poder de oferecer um tipo de liderança personalizada, crucial para promover agendas urbanas e erigir um perfil internacional da cidade.

Outro argumento balizador é a ideia de que a forma como as cidades abordam as questões climáticas está intrinsecamente relacionada a alguns aspectos e configurações locais que interferem, em maior ou menor grau, nos seus processos de adaptação às mudanças climáticas. Entre eles podem ser listados o nível de exposição aos efeitos das mudanças climáticas de sua população e alguns elementos que influenciam direta e indiretamente o potencial e a capacidade de as cidades enfrentarem impactos ou riscos às mudanças climáticas (ANGUELOVSKI; CARMIN, 2011; BULKELEY; BROTO, 2013; EAKIN et al., 2014; PELLING; HIGH, 2005; UITTENBROEK et al., 2014; WISE et al., 2014).

Detalhado na próxima seção, o artigo ancora-se em um conjunto de métodos adotados na pesquisa realizada, incluindo pesquisa documental; observações de reuniões e eventos; realização de entrevistas e reuniões com atores/grupos de interesse (na escala macro da cidade, e na escala micro, em uma subprefeitura de São Paulo); e realização de um workshop.

Os autores discutem mudanças climáticas e cidades, na perspectiva das projeções climáticas e especificidades de São Paulo, refletindo sobre a premissa de que a forma como o município enfrenta o fenômeno climático está intrinsecamente relacionada a fatores que influenciam direta e indiretamente 
as respostas que podem emergir. A seguir, discutem o papel que o poder local tem no processo de buscar sinergias entre adaptação, mitigação e desenvolvimento por meio da experimentação, testando diferentes abordagens sociais e tecnológicas. Para tanto, são apresentadas e discutidas algumas ações implementadas em São Paulo com potencial para responder aos desafios climáticos, com um foco nas ações que não são relacionadas diretamente ao discurso climático. Finalmente, sinalizam alguns desafios para a megacidade de São Paulo, a partir de suas próprias especificidades e complexidades nos planos econômico, político e social.

\section{PROCEDIMENTOS DA PESQUISA}

Tendo como recorte temporal os anos de 2014 e 2015 e uma abordagem de pesquisa qualitativa e exploratória, privilegiando a interação de atores sociais da ciência, política e sociedade civil, o estudo envolveu pesquisa documental, com análises de resultados de inquéritos de opinião pública realizados na cidade de São Paulo sobre meio ambiente (Datafolha Instituto de Pesquisas, 2014), mobilidade urbana (Rede Nossa São Paulo e Ibope, 2015), avaliação da gestão local (Datafolha Instituto de Pesquisas, 2015) e crise hídrica² (Datafolha Instituto de Pesquisas, 2015). Na pesquisa documental, buscou-se também analisar entrevistas concedidas à mídia pelo então prefeito da cidade, Fernando Haddad (PT), a partir de consulta a sites de busca, ancorando-se em duas perspectivas analíticas, que serão discutidas neste artigo: (i) experimentação de políticas públicas (policy experimentation) e empreendedores de políticas públicas (policy entrepreneurs ou municipal champions). Foram analisados ainda documentos relacionados ao Plano Diretor Estratégico (2014) e ao Plano Municipal de Mobilidade Urbana (2015).

Empiricamente e privilegiando um enfoque em dois níveis de análise, a pesquisa explorou no nível mais amplo as respostas da gestão pública do município ao fenômeno climático e no nível micro uma região específica da cidade, a subprefeitura do Butantã, localizada na zona oeste. A escolha pela localidade está relacionada ao último estudo de mapeamento das áreas de risco de São Paulo, realizado pelo Instituto de Pesquisa Tecnológica (IPT), em 2010, que mapeou, na subprefeitura do Butantã, 21 áreas de risco, considerando dois processos geofísicos analisados (escorregamentos e solapamentos). Cabe ressaltar que essa região da cidade é representativa da diversidade de São Paulo, abrigando desde a Cidade Universitária/USP e setores tidos como mais abastados a diversos assentamentos precários em áreas de risco.

Para dar conta dessa análise multinível, foram realizadas entrevistas semiestruturadas e reuniões com diferentes atores/grupos sociais. No período da pesquisa, foram entrevistados pesquisadores do IPT, envolvidos no mapeamento de áreas de risco da cidade; jornalistas que cobrem questões ambientais e urbanas em São Paulo; e representantes de organizações não governamentais (ONGs) que atuam em São Paulo, incluindo Observatório do Clima, rede que reúne entidades da sociedade com o objetivo de discutir a questão das mudanças climáticas no contexto brasileiro; Rede Nossa São Paulo, que integra organizações da sociedade civil com o objetivo de construir uma agenda visando uma cidade mais justa e sustentável; e Andi - Comunicação e Direitos, organização da sociedade civil que articula ações em mídia para o desenvolvimento sustentável e direitos humanos.

Foram realizadas entrevistas com representantes das Secretarias Municipais do Verde e Meio Ambiente, Desenvolvimento Urbano e Transporte. Ainda no período houve reuniões com integrantes de uma rede mobilizada em torno de questões da subprefeitura do Butantã; com membros da equipe da Secretaria Municipal de Habitação e da Defesa Civil; com lideranças da área reurbanizada da antiga favela do Real Parque, localizada na subprefeitura do Butantã (área que já foi considerada de risco e de ocupação irregular e que, agora, passa por um processo de reurbanização); e com integrantes do Conselho Municipal do Meio Ambiente e Desenvolvimento Sustentável (Cades) do Butantã. Nessas reuniões foi possível apresentar a pesquisa e debater questões ambientais e urbanas da cidade e dessa região específica.

Quanto à observação, foi priorizado acompanhamento de reuniões do Comitê de Mudanças do Clima e Ecoeconomia da Prefeitura Municipal de São Paulo, que tem o objetivo de promover ações relativas a questões ambientais e atividades que apoiem o combate à mudança do clima; e de reuniões da rede 
mobilizada em torno de questões da subprefeitura do Butantã. Foram ainda acompanhados eventos realizados ao longo desse período na cidade de São Paulo, focados na questão climática e eventos extremos.

Como parte dos procedimentos metodológicos da pesquisa, cabe destacar ainda a organização e realização do workshop "Adaptação climática em megacidades: refletindo sobre impactos, demandas e capacidades de resposta de São Paulo", em 2014, que contou com a participação de grupos com forte influência nos processos decisórios sobre questões ambientais e urbanas, incluindo agentes públicos, acadêmicos e jornalistas especializados, que buscaram refletir sobre formas adaptativas em São Paulo.

O conjunto de dados obtidos, analisado desde uma perspectiva temática (DUARTE, 2004) e de conteúdo (BARDIN, 1977), embasa as análises, discussões e reflexões propostas a seguir dentro do escopo deste artigo.

\section{MUDANÇAS CLIMÁTICAS, ADAPTAÇÃO E CIDADES}

Desde o primeiro relatório do Painel Intergovernamental sobre Mudanças Climáticas (IPCC) tem sido colocada a necessidade da desaceleração do processo de aquecimento global, por meio de um esforço político e econômico mundial urgente, que aja tanto na contenção e redução de emissões de gases de efeito estufa em medidas de mitigação, em um curto prazo, como na implementação de medidas de adaptação, no longo prazo. As megacidades, definidas como aquelas com mais de 10 milhões de habitantes, como São Paulo, sofrem grandes transformações atuais e têm papel fundamental nesse processo. Nelas ocorrem os modos de vida associados à urbanização, que são um dos principais motores das mudanças ambientais em curso (IPCC, 2007, 2013).

Especialmente nos países não centrais, as cidades são tidas como as áreas mais suscetíveis a enfrentarem os impactos mais severos das alterações climáticas, como eventos extremos de precipitação e associados à temperatura e seca (CLIMATE AND DEVELOPMENT KNOWLEDGE NETWORK, 2012; IPCC, 2007, 2013; NOBRE et al., 2010; RIBEIRO, 2008). Para a maior parte dessas cidades, há necessidade de que ações e medidas de mitigação e adaptação estejam atreladas à política habitacional, ao saneamento, aos planos diretores, à política e gestão de recursos hídricos e à revisão das formas de mobilidade urbana (BUENO, 2013).

Com uma população de mais de 12 milhões de habitantes (mais de 15\% em assentamentos precários - CEM/Cebrap e Fundap, 2013), vivendo em uma área de 1.521,101 Km² (IBGE, 2013), São Paulo demonstrou por anos atrasos e fragilidades tanto em termos de desenvolvimento de tecnologias sociais como de atenção dos poderes públicos em acompanhar o crescimento urbano e propor ações voltadas ao ordenamento territorial (DI GIULIO; VASCONCELLOS, 2014). Na esteira dos problemas urbanos, a megacidade enfrenta ainda efeitos da variabilidade climática e das mudanças climáticas associadas às ações antrópicas. Ilhas de calor, que não só dificultam a dispersão dos poluentes como potencializam a ocorrência de chuvas torrenciais (LOMBARDO, 1985), e eventos extremos que potencializam episódios de enchentes ou de secas, como a registrada entre 2014 e 2015 (COHEN, 2016; MARENGO et al., 2015; NOBRE et al., 2016), ganham cada vez mais concretude, trazendo consequências ao cotidiano de seus moradores.

As projeções climáticas para este século para a capital paulista reforçam este alerta, indicando alterações na distribuição, intensidade e frequência geográfica dos riscos relacionados às condições meteorológicas, ameaçando exceder as capacidades da megacidade de absorver perdas e recuperar-se dos impactos (AMBRIZZI et al., 2012).

Ainda que haja incertezas, as projeções tanto dos modelos globais como dos modelos regionais para a Região Sudeste, onde está a cidade de São Paulo, sinalizam aumento de dias secos consecutivos; redução do número de dias úmidos; concentração de chuvas intensas em períodos curtos; diminuição do número de noites frias; e aumento do número de noites quentes, com temperaturas mínimas elevadas (TORRES, 2016). Os dados referentes ao índice de desconforto térmico apontam que ele deve aumentar, o que deve ser objeto de atenção crescente, especialmente por parte dos setores de saúde 
e planejamento energético, já que com temperaturas mais altas, há maior tendência, por exemplo, de uso de ar-condicionado (TORRES, 2016).

Ao pensar nas mudanças climáticas, Torres (2016) argumenta que a difícil previsibilidade climática para a Região Sudeste não deve impedir ou atrasar medidas adaptativas e mitigadoras a serem adotadas. Ao contrário, no caso de São Paulo, a megacidade deve investir em medidas "no-regrets" (sem arrependimentos), relacionadas a diversos setores da gestão municipal, como drenagem urbana, resíduos, uso e ocupação do solo, mobilidade, arborização, serviços ambientais, por exemplo, cujas ações têm impacto direto na cidade e na qualidade de vida dos seus moradores. Nesse sentido, decisões, como ações preventivas e intervenções que privilegiem sinergias com outros objetivos da vida urbana, como sustentabilidade e potenciais inovações sociais e de infraestrutura, devem ser priorizadas (DENTON et al., 2014).

\subsection{DISCUTINDO ADAPTAÇÃO CLIMÁTICA}

Entendendo adaptação como processos de ajustamentos para antecipar impactos adversos das mudanças climáticas que resultam na redução da vulnerabilidade (IPCC, 2007) e capacidade adaptativa como o potencial de mudar para um estado mais desejável frente aos impactos ou riscos às mudanças climáticas (EAKIN et al., 2014), partimos da ideia de que a forma como as cidades (incluindo o poder local e a sociedade) lidam com esse fenômeno está intrinsecamente relacionada a determinados aspectos e configurações locais que interferem, em maior ou menor grau, nos processos adaptativos da cidade. Essas respostas e arranjos também são impactados direta e indiretamente por dois fatores: (i) as percepções dos riscos associados a esse fenômeno; (ii) os impactos dos eventos climáticos extremos e o aumento da vulnerabilidade.

No que tange ao primeiro fator, estudos que buscam analisar as diferentes percepções sobre mudanças climáticas e sobre os riscos associados ou potencializados por elas reconhecem diversos elementos sociais e culturais que influenciam direta e indiretamente as percepções dos indivíduos. As análises publicadas mostram que, apesar de haver uma sensibilização generalizada e difusa sobre as questões climáticas, a maioria dos indivíduos tem dificuldades em compreender causas e efeitos dessas alterações (GIDDENS, 2009; LEISEROWITZ et al., 2012; ORESKES, 2007; RENN, 2011; WEBER, 2010), as quais aparecem como uma prioridade relativamente baixa se comparadas a outras questões (mesmo ambientais) que pressionam o mundo ou os países (LEISEROWITZ, 2007, 2008).

Com relação aos impactos dos eventos climáticos extremos e o aumento da vulnerabilidade, a série de eventos registrados desde a década de 2000 certamente teve seu peso para que a adaptação climática ganhasse evidência nas agendas políticas internacionais (LINDOSO, 2015) e refletisse diretamente no debate e ações do poder local. No caso brasileiro, especificamente, ainda que acordos globais e o contexto internacional tenham peso relevante nas políticas nacionais propostas (BACK, 2012; FERREIRA; BARBI, 2016; RIBEIRO, 2010; SETZER et al., 2015; VIOLA; FRANCHINI, 2012), é possível pensar que o aumento da frequência de eventos climáticos extremos refletiu, em certa medida, na elaboração de políticas públicas, como o Plano Nacional sobre Mudança do Clima, criado em 2008; a Política Nacional sobre a Mudança do Clima, em 2009; a Política Nacional de Proteção e Defesa Civil e o Centro Nacional de Monitoramento e Alertas de Desastres Naturais (Cemaden), em 2012; e mais recentemente o Plano Nacional de Adaptação à Mudança do Clima, em 2016.

\subsection{A RELAÇÃO ENTRE ESSES FATORES E CAPACIDADE ADAPTATIVA NA MEGACIDADE DE SÃO PAULO}

Esses fatores discutidos no item anterior pesam na capacidade das cidades de se adaptarem às mudanças climáticas e nas respostas que emergem para lidar com os impactos climáticos que se constituem, muitas vezes, como uma exacerbação dos riscos já existentes em seus territórios, resultantes das inadequações nas capacidades dos governos locais para tratar do enorme déficit na infraestrutura e de serviços básicos necessários (DI GIULIO; VASCONCELLOS, 2014). Em São Paulo não é diferente. Tais fatores pesam no debate sobre a questão climática e dificultam delinear as respostas que surgem 
(ainda que com menor força ante a seriedade do problema), seja no âmbito individual, coletivo e institucional.

Quanto às percepções de risco, os dados analisados no estudo conduzido revelam o que chamamos de certo "olhar míope" dos indivíduos para a questão climática (DI GIULIO; VASCONCELLOS, 2014), já que a opinião pública paulistana reconheceria os efeitos das alterações climáticas, mas ainda colocaria o clima como um problema menor; os impactos climáticos, embora preocupantes, disputariam com outras questões (ainda que da esfera ambiental) que pressionariam mais os indivíduos. A análise do material coletado, particularmente das entrevistas conduzidas com representantes de organizações não governamentais (ONGs) que atuam em São Paulo, revela que a questão climática ainda não está posta nas agendas pública e política como deveria. Na entrevista realizada com o secretário-executivo do Observatório do Clima, o "comodismo" da sociedade em geral e da brasileira, especificamente para a questão climática, é apontado como um dos entraves para um debate público mais amplo sobre o tema e para a proposição de ações efetivas. Na mesma direção, o coordenador-executivo da Rede Nossa São Paulo reconhece que a questão climática, no nível local, ainda não está posta.

Transpondo essas observações para a subprefeitura do Butantã, também é possível aferir que as mudanças climáticas não são percebidas como problema urgente. Nas reuniões realizadas com os diferentes grupos de interesse, é possível observar que outras questões estão na agenda de prioridade e ganham voz nas discussões sobre problemas urbanos e ambientais, como mobilidade, crise hídrica e uso e ocupação do solo - ainda que todas elas tenham interfaces com a questão climática.

Essas "barreiras sociais e perceptivas", que dificultariam a identificação e priorização dos riscos climáticos (LITRE; BURSZTYN, 2015) e pesariam nas representações sociais (SPINK, 1993) sobre as mudanças climáticas e os impactos negativos associados a elas na escala local, teriam reflexos também nas ações praticadas pela gestão pública da cidade quanto à questão climática? É possível que sim.

Em São Paulo, como os resultados da pesquisa evidenciam, as ações e intervenções propostas não estão associadas, diretamente, ao discurso climático. Consistente com o que descreve a literatura internacional enfocando "climate mainstreaming", existe uma clara oportunidade de "casar" ações relacionadas ao clima com outras ações dentro do desenvolvimento da metrópole que facilitem o engajamento de quadros da administração e potencializem resultados na intersecção de diversos setores como mitigação, adaptação e desenvolvimento sustentável (BARCLAY et al., 2013; DENTON et al., 2014). Esse ponto será abordado com mais profundidade na seção 4 deste artigo.

Quanto aos impactos dos eventos climáticos extremos e o aumento da vulnerabilidade, a realização do workshop "Adaptação climática em megacidades: refletindo sobre impactos, demandas e capacidades de resposta de São Paulo" mostrou que a questão da água também pode ser um direcionador para um debate ampliado sobre as questões climáticas e para as ações no nível local. Problemas de gestão dos recursos hídricos foram debatidos de forma transversal e relacionados tanto à discussão sobre mudanças climáticas, como à capacidade adaptativa da megacidade.

Na microescala do estudo, tomando como base as observações e realização de entrevistas e reuniões com grupos de interesse na subprefeitura do Butantã, é possível afirmar que a escassez de chuva também refletiu nos debates e ações dos moradores, despertando discussões, cobranças para o poder público e ações individuais e coletivas. Contudo, ao analisar o material coletado, é possível observar que esses grupos expressaram dúvidas se a falta d'água continuaria a ter reflexos nas mudanças de comportamentos e práticas individuais. Na análise dos dados obtidos, é possível observar que tais mudanças de comportamentos seriam mais percebidas como diretamente atreladas às medidas políticas, como posturas e incentivos do governo, e às próprias sensibilidades e resistências individuais. Essas percepções vão ao encontro da próxima ideia discutida neste artigo: a de que o poder local tem papel relevante no processo de buscar sinergias entre adaptação, mitigação e desenvolvimento por meio da experimentação, testando diferentes abordagens sociais e tecnológicas para responder às mudanças climáticas no nível local. 


\section{INDÍCIOS DE EXPERIMENTAÇÃO E ADAPTAÇÃO CLIMÁTICA EM SÃO PAULO}

A experimentação de políticas públicas (policy experimentation) nos espaços urbanos surge como importante opção para aqueles que pretendem tomar medidas climáticas tendo em vista possíveis ganhos econômicos, redução dos potenciais perigos associados aos impactos climáticos, expansão de reivindicações de autoridade ou de recursos ou, ainda, expressão de uma posição ideológica sobre o fenômeno climático (HOFFMANN, 2011). Uma leitura dos resultados e análises de pesquisas internacionais focadas em compreender ações adaptativas em cidades revela que as experimentações de políticas públicas vão sendo construídas dentro do contexto nas quais emergem, sendo influenciadas por diferentes variáveis, como: (i) as cidades buscam políticas inovadoras de mudanças climáticas porque isso pode ajudá-las a cumprir suas próprias metas internas ou reduzir riscos (ANGUELOVSKI; CARMIN, 2011; BASSETT; SHANDAS, 2010); (ii) as cidades tomam iniciativa para agir diante das mudanças climáticas porque essa é uma forma de se diferenciar positivamente e alcançar posições de lideranças, promovendo seus perfis e afirmando sua capacidade de exercer pressão política sobre escalas mais altas de governança (ANGUELOVSKI; CARMIN, 2011); (iii) as cidades seguem com a questão climática como uma forma de alcançarem outros objetivos, como iniciativas verdes ou sustentabilidade, justiça social, redução de despesas potenciais, suporte ao desenvolvimento econômico, atração de investimento e migração econômica (BARCLAY et al., 2013).

Nesse sentido, as respostas ao fenômeno climático e a perspectiva de adaptação podem (e muitas vezes é) estar integradas às políticas públicas e ações já existentes, como planejamento urbano, gerenciamento de recursos hídricos e saúde pública - na literatura internacional, essa abordagem é chamada de mainstreaming approach (UITTENBROEK et al., 2014). Como ressaltam esses autores, ao contrário da chamada "abordagem dedicada" (dedicated approach), na qual a adaptação climática é apresentada como uma nova proposta de política (new policy domain), nessa perspectiva, as respostas de adaptação climáticas são organizadas buscando-se sinergias com as políticas e recursos já existentes. Adaptação climática é considerada, assim, um valor adicional a outro objetivo.

Em São Paulo, a questão climática está na agenda local desde 2003, quando a cidade passou a integrar a campanha Cities for Climate Protection, iniciativa liderada pelo ICLEI - Local Governments for Sustainability, principal associação mundial de governos locais e subnacionais dedicados ao desenvolvimento sustentável. Em 2005, a cidade passou a integrar o C40 - Cities Climate Leadership Group, que reúne cidades ao redor do mundo comprometidas em reduzir as emissões de gases de efeito estufa e reduzir as ameaças climáticas. A adesão a essas iniciativas, como reconhecem Setzer et al. (2015), encorajou o governo local de São Paulo a assumir compromissos para reduzir as emissões, incluindo a realização de inventários e a proposição da Política Municipal de Mudança do Clima (Lei n. 14.933), instituída em 2009, cujos eixos de estratégias são transporte, gerenciamento de resíduos, uso do solo, energia, construções sustentáveis e saúde (BACK, 2012; CORTESE, 2013; FURRIELA, 2011).

Mais recentemente, com o Plano Diretor Estratégico (PDE) e o Plano Municipal de Mobilidade Urbana, São Paulo sinaliza intervenções mais ajustadas às questões ambientais e climáticas sem, contudo, parecer ter adotado esses termos para justificar suas proposições. Considerando os resultados do inventário das emissões de São Paulo de 2011, que apontou que $61 \%$ das emissões de gases de efeito estufa estão relacionadas à mobilidade ( $15 \%$ aos resíduos, $20 \%$ energia, $4 \%$ outros e $0,1 \%$ uso de solo), é possível pensar que tal dado, aliado à premissa de que transporte e mobilidade têm sido um dos principais gargalos da cidade, colaborou para que a gestão pública municipal focasse essas questões dentro de suas ações prioritárias. Algumas ações colocadas em prática, como a instalação de faixas exclusivas de ônibus e a implantação de ciclovias e ciclofaixas, sinalizam que a gestão municipal, no período estudado, buscou soluções "orientadas para o interesse coletivo, em termos tanto sociais como econômicos e ambientais" (WISNIK, 2014).

Contudo, Bonduki (2014), ao refletir sobre o PDE à luz da Política Municipal das Mudanças Climáticas, mostra que, para além das ações de mobilidade, outras propostas do plano estão relacionadas à questão climática, evidenciando sinergias entre mitigação e adaptação, como a criação da zona rural da cidade com um plano de desenvolvimento sustentável, pagamento de serviços ambientais para áreas protegidas, estímulo à moradia em regiões onde há mais ofertas de emprego, criação de polos 
de desenvolvimento econômico nas regiões que concentram moradias e incentivo à implantação de parques transformados em Zonas Especiais de Proteção Ambiental (Zepam). Outras ações propostas no PDE também são compatíveis com a questão climática, como apoio à cidade compacta; redução da geração de resíduos, coleta seletiva, reciclagem e compostagem; incentivo às edificações que contribuam para a redução das emissões de gases de efeito estufa; sistema de áreas protegidas, áreas verdes e espaços livres; e proteção aos remanescentes da Mata Atlântica (BONDUKI, 2014).

Apesar das interfaces que essas propostas têm com a questão climática, tais soluções postuladas pela cidade não estão coladas ao discurso climático, mas integradas às políticas públicas e ações já existentes, particularmente relacionadas a planejamento urbano, dialogando, assim, com o que propõe a perspectiva de mainstreaming approach (UITTENBROEK et al., 2014).

Como a análise dos resultados obtidos na pesquisa sugere, as ações de mobilidade urbana implementadas em São Paulo, que buscam priorizar o transporte público e a bicicleta em detrimento do automóvel, também confirmam essa opção pelo discurso não climático. Em entrevista com o secretário de Transportes do município de São Paulo, realizada em 2015, as ações de mobilidade discutidas e implementadas em São Paulo foram associadas muito mais à necessidade de "enxergar a cidade como uma cidade aberta", confrontando, assim, com o maior problema da megacidade paulista, hoje, "que é o espaço público" - ainda que haja um reconhecimento de que o Plano Municipal de Mobilidade Urbana, aprovado em 2015, dialoga com o tema climático, incluindo metas para questões ambientais e climáticas.

Essa estratégia, a de promover ações sem relacioná-las diretamente ao discurso climático, mas adotando termos como "crescimento inteligente", "infraestrutura verde", por exemplo, tem sido adotada por gestores de outras cidades, inclusive no âmbito internacional (BARCLAY et al., 2013). Como em São Paulo, projetos de outras naturezas, como resíduos e mobilidade, temas eminentemente locais ou intermunicipais, são colocados como fundamentais para o desenvolvimento das cidades, e podem se constituir, na prática, como ações adaptativas.

Se o slogan das mudanças climáticas ainda parece ter conotação negativa - seja porque a percepção desse fenômeno e dos seus riscos é baixa; seja porque na esfera pública outros problemas são reconhecidos como mais urgentes e, portanto, devem ser condicionantes das ações e políticas públicas (como a própria questão da mobilidade, no caso de São Paulo); ou, ainda, porque os custos de apresentar estratégias de adaptação climática como uma nova proposta de política pública são altos -, a adoção de uma agenda socioambiental em São Paulo, e não de uma agenda ambiental e/ou climática, pode ser uma mudança positiva.

Nesse sentido, destaca-se a relevância dos chamados empreendedores de políticas públicas (policy entrepreneurs, municipal champions ou institutional entrepreneurs): atores que têm papel fundamental na emergência de políticas públicas voltadas a uma agenda socioambiental mais atrelada às questões climáticas. Os policy entrepreneurs buscariam, por meio das próprias estruturas existentes e da mobilização de outros atores e recursos (UITTENBROEK et al., 2014), alcançar ações adaptativas por meio de experimentações (ANGUELOVSKI; CARMIN, 2011; BARCLAY et al., 2013; BULKELEY; BROTO, 2013).

A análise de entrevistas concedidas à mídia pelo então prefeito da cidade (Fernando Haddad, PT, que governou São Paulo entre os anos de 2013 e 2016) e compiladas na pesquisa realizada corrobora a ideia de promoção de ações não coladas ao discurso climático e a ideia de construção de uma agenda socioambiental articulada às experimentações. Os trechos a seguir exemplificam esses apontamentos: "[...] A agenda ambiental às vezes esconde um certo acanhamento de não querer colocar o dedo nas feridas que o Brasil tem abertas ainda. Mas uma agenda socioambiental tem como pactuar classes médias antenadas, que viajam e olham o que acontece no mundo. Estou tentando explorar isso em São Paulo porque se der essa liga, vai ajudar a cidade a vislumbrar um futuro diferente" ${ }^{\prime 3}$; “[...] pretensões de que São Paulo não se veja mais como cidade terceiro-mundista. Já criticavam as faixas de ônibus em 2013. Em 2014, foi a vez da ciclovia. Tem uma agenda de curto prazo, que é mais simbólica. Nunca mais São Paulo vai ver o transporte público como via no passado [...] Esse paradigma do carro e asfalto está sepultado [...]"4. 


\section{DESAFIOS PARA A MEGACIDADE DE SÃO PAULO}

As respostas que São Paulo tem dado às mudanças climáticas precisam estar conectadas às questõeschave da governança urbana, reconhecendo as especificidades e complexidades da cidade nos planos econômico, político e social. Certamente essas conexões são influenciadas também por outros elementos discutidos na literatura relacionados à capacidade adaptativa das cidades e que podem ser entendidos como aspectos ainda caros à megacidade paulista.

O primeiro deles refere-se aos acessos e usos das informações científicas nas decisões tomadas. A forma como as informações técnicas e científicas são divulgadas publicamente (divulgação científica) ganha expressivo destaque como mediação das relações das pessoas com o ambiente social e materializado. $\mathrm{O}$ conhecimento sobre as opções disponíveis, a capacidade de acessá-las e a habilidade para implementar aquelas mais adequadas é fundamental nesse processo, já que "... o déficit entre o que é preciso saber para facilitar a adaptação e o que se sabe ('o déficit da adaptação') é particularmente grande" (CARVALHO; FURTADO, 2015, p. 7).

Com base nos dados coletados e analisados na pesquisa realizada é possível fazer dois apontamentos quanto a esse elemento: (i) ainda há uma distância entre academia e gestão pública, reverberada inclusive em relações de desconfiança e de não colaboração entre os grupos - fato evidenciado particularmente no workshop realizado em São Paulo para discutir ações adaptativas na megacidade diante das mudanças climáticas; (ii) a divulgação das informações geradas pelos estudos científicos ainda apresenta lacunas, dificultando o entendimento e a apropriação do conhecimento.

Quanto aos recursos econômicos e à capacidade tecnológica, Fankhauser e McDermott (2014) mostram que o déficit de adaptação (adaptation deficit) passa pela ausência (ou ineficiência) de capacidade tecnológica, institucional e financeira. No nível de uma cidade (ou ainda no nível individual), há certamente uma relação estreita entre investimentos para reduzir a vulnerabilidade a eventos extremos ou estar melhor preparado para enfrentá-los e a disponibilidade de recursos econômicos (EAKIN et al., 2014).

Os recursos econômicos e a capacidade tecnológica influenciam, ainda, a realização de estudos de clima urbano, com amplas séries temporais e espaciais de dados, e análises climatológicas. Consequentemente, discutir e dar respostas sobre qual é a vulnerabilidade da população e da cidade e quais as medidas de adaptação e mitigação que devem ser tomadas não são tarefas simples e precisam ser mais investigadas, particularmente considerando o processo de urbanização de São Paulo, caracterizado pela desigualdade no acesso aos bens e serviços públicos (CARLOS, 2004).

Finalmente, quanto aos processos de governança participativos, Walker et al. (2012) chamam atenção para a relevância de um processo de governança inclusivo e baseado em multiníveis para fomentar a adaptação. Instituições, governança e gestão são fatores críticos que influenciam a capacidade de um sistema na adaptação às mudanças climáticas (ENGLE; LEMOS, 2010).

No caso de São Paulo, como a pesquisa realizada mostrou, se por um lado a gestão passada parecia ter o cuidado em aprimorar e ampliar as instâncias participativas, fortalecendo instituições como Conselhos Participativos e implementando iniciativas como "Participação Digital" e aplicativos digitais, por outro, era apontada como uma gestão que "implementa novas políticas sem estabelecer previamente canais de diálogo com os cidadãos", optando, assim, por uma "via tecnocrática" e "abdicando-se da tentativa de construir consensos e reduzir resistências a políticas que - justamente em função de seu caráter inovador - não estavam incorporadas ao senso comum dos cidadãos" (COUTO, 2015).

\section{CONSIDERAÇÕES FINAIS}

Não resta dúvida de que as mudanças climáticas lançam enormes desafios para a sociedade contemporânea. Eles se tornam ainda maiores quando se trata de uma megacidade com as condições e os contrastes sociais e econômicos de São Paulo. 
Ao analisar e refletir sobre a experiência em curso da megacidade quanto às questões climáticas, é possível destacar alguns apontamentos importantes. Se por um lado as mudanças climáticas ainda são percebidas como um problema menor e precisariam ganhar força e visibilidade nas agendas pública e política, por outro é possível observar que os impactos dos eventos meteorológicos extremos podem ter algum efeito e serem direcionadores para um debate mais ampliado sobre as mudanças climáticas e implementação de ações no nível local - como evidenciado por exemplo pela crise hídrica.

Ao considerar o papel relevante do poder local no processo de buscar sinergias entre adaptação, mitigação e desenvolvimento por meio de experimentações, a análise da experiência em curso em São Paulo evidencia duas importantes perspectivas: as propostas do Plano Diretor Estratégico (PDE) e as ações de mobilidade urbana adotadas na gestão passada e compatíveis com a questão climática. Esses projetos e a adoção de uma agenda socioambiental são fundamentais para o desenvolvimento da cidade e podem se constituir na prática como ações de resposta às mudanças climáticas. Apesar da dificuldade em assumir claramente um discurso que assimile as mudanças climáticas, parte das ações propostas pelo Executivo paulistano pode gerar um resultado positivo na direção das necessárias medidas que busquem sinergias entre mitigação e adaptação que a cidade exige. Contudo, é fundamental enfrentar com determinação aspectos importantes para o desenvolvimento da cidade, que vão desde moradias irregulares dispostas em áreas de risco a questões relacionadas à gestão de resíduos e segurança hídrica alimentar, por exemplo.

A análise sobre a experiência em curso da megacidade de São Paulo contribui para o debate nacional e internacional sobre respostas locais às mudanças climáticas e evidencia a necessidade de avançar na construção de um modelo teórico-analítico, que considere as especificidades do contexto brasileiro e um conjunto de variáveis críticas que refletem na capacidade adaptativa das cidades brasileiras.

\title{
AGRADECIMENTOS
}

Os autores agradecem à Fapesp (Processos 2013/17665-5 e 2014/50313-8) e ao CNPq (446032/2015-8).

\author{
NOTAS \\ ${ }^{1}$ Algumas das ideias discutidas neste artigo foram inicialmente apresentadas no $7^{\circ}$ Enanppas, 2015, Brasília. 7ํㅡ Encontro Nacional da \\ Anppas - Anais, 2015 \\ ${ }^{2}$ Nos anos de 2014 e 2015 o município de São Paulo enfrentou uma forte crise de abastecimento hídrico causado, entre outros aspec- \\ tos, pela gestão mercantilista da água pela empresa concessionária do serviço - Sabesp, associada a uma estiagem prolongada. Entre as \\ alternativas sugeridas pelos gestores, que não integram o poder municipal, estava a alteração do preço da tarifa de modo a onerar os que \\ aumentaram o consumo e a desonerar os que o baixaram. \\ ${ }^{3}$ Disponível em: <http://www.capital.sp.gov.br/portal/noticia/5089>. Acesso em: 30 jun. 2015. \\ ${ }^{4}$ Disponível em: <http://epoca.globo.com/tempo/noticia/2015/02/bfernando-haddad-bninguem-suporta-mais-corrupcao.html>. Acesso \\ em: 17 nov. 2015.
}

\section{REFERÊNCIAS}

AMBRIZZI, T. et al. Sumário Executivo do Volume 1 - Base Científica das Mudanças Climáticas. Contribuição do Grupo de Trabalho 1 para o 1ำ Relatório de Avaliação Nacional do Painel Brasileiro de Mudanças Climáticas. PBMC, Rio de Janeiro, Brasil, 2012. 34 p.

ANGUELOVSKI, I.; CARMIN, J. Something borrowed, everything new: innovation and institutionalization in urban climate governance. Current Opinion in Environmental Sustainability, v. 3, n. 3, p. 169-175, 2011.

BACK, A. G. Política paulistana de mudança climática: agenda-setting e desenvolvimento político-institucional. 2012. Disponível em: <http://www.anppas.org.br/encontro6/anais/ARQUIVOS/GT11-794-493-20120621193331. pdf>.

BARCLAY, P. et al. Climate change adaptation in Great lakes Cities. University of Michigan Masters Capstone. 2013. 
BASSEST, E.; SHANDAS, V. Innovation and climate action planning. Journal of the American Planning Association, v. 76, n. 4 , p. 435-450, 2010.

BECK, U. The Cosmopolitan Society and its Enemies. Theory, Culture \& Society, v. 19, p. 17-44, 2002.

BONDUKI, N. Plano Diretor de São Paulo não inviabiliza mercado imobiliário, mas regula a sua atuação. 2014. Disponível em: <http://noticias.uol.com.br/opiniao/coluna/2014/06/16/plano-diretor-de-sao-paulo-naoinviabiliza-mercado-imobiliario-mas-regula-a-sua-atuacao.htm>. Acesso em: 17 jun. 2014.

BUENO, L. M. M. A adaptação da cidade às mudanças climáticas: uma agenda de pesquisa e uma agenda política. In: OJIMA, R.; MARANDOLA JR., E. Mudanças climáticas e as cidades: novos e antigos debates na busca da sustentabilidade urbana e social. São Paulo: Blucher, 2013.

BULKELEY, H.; BROTO, V. "Government by Experiment? Global Cities and the Governing of Climate Change." Transactions of the Institute of British Geographers, v. 38, p. 361-75, 2013.

CARLOS, A. F. A. O espaço urbano. São Paulo: Contexto, 2004.

CARVALHO, S. A. D.; FURTADO, A. T. Os desafios da adaptação às mudanças climáticas globais. In: ClimaCom Cultura Científica: pesquisa, jornalismo e arte, ano 02, n. 02. Disponível em: <http://climacom.mudancasclimaticas. net/?p=1927>. Acesso em: 18 nov. 2015.

CLIMATE AND DEVELOPMENT KNOWLEDGE NETWORK. Gerenciando extremos climáticos e desastres na América Latina e no Caribe: lições do relatório SREX vargas. 2012. Disponível em: <http://www.fapesp.br/ipccsrex/upload/ SEX-Lessons-Portuguese-LAC.pdf>. Acesso em: 27 dez. 2012.

COHEN, D. A. The Rationed City: the politics of water, housing, and land use in Drought-Parched. Public Culture, v. 28, n. 2, p. 261-289, 2016.

COUTO, C. G. Fernando Haddad: a ousadia sem diálogo. Disponível em: <http://politica.estadao.com.br/blogs/ gestao-politica-e-sociedade/fernando-haddad-a-ousadia-sem-dialogo/>. Acesso em: 16 ago. 2016.

DENTON, F. et al. Climate-resilient pathways: adaptation, mitigation, and sustainable development. In: Climate Change. 2014: Impacts, Adaptation, and Vulnerability. Part A: Global and Sectorial Aspects. Contribution of Working Group II to the Fifth Assessment Report of the Intergovernmental Panel on Climate Change 2014. p. 1101-1131.

DI GIULIO, G. M.; VASCONCELLOS, M. P. Contribuições das Ciências Humanas para o debate sobre mudanças ambientais: um olhar sobre São Paulo. Estudos Avançados (USP. Impresso), v. 28, p. 41-63, 2014.

EAKIN, H., LEMOS, M. C.; NELSON, D. Differentiating capacities as a means to sustainable climate change adaptation. Global Environmental Change, v. 27, p. 1-8, 2014.

ECHEGARAY, F.; AFONSO, M. H. F. Respostas às mudanças climáticas: inovação tecnológica ou mudança de comportamento individual? Estudos Avançados, São Paulo, v. 28, n. 82, dez. 2014. Disponível em: <http://www. scielo.br/scielo.php?script=sci_arttext\&pid=S0103-40142014000300010\&lng=pt\&nrm=iso>. Acesso em: 17 dez. 2014.

ENGLE, N.; LEMOS, M. C. Unpacking Governance: building adaptive capacity to climate change of River Basins in Brazil. Global Environmental Change, v. 20, p. 4-13, 2010.

FERREIRA, L. C.; BARBI, F. The Challenge of Global Environmental Change in the Antropocene: an analyis of Brazil and China. Chinese Political Science Review, v. x, p. 1-13, 2016.

GIDDENS, A. The politics of climate change. Cambridge: Polity Press, 2009.

Sociologia. 4. ed. Porto Alegre: Artmed, 2005.

HOFFMANN, M. J. Climate governance at the crossroads: experimenting with a global response. New York: Oxford University Press, 2011. 
HOGAN, D. (Org.) Dinâmica populacional e mudança ambiental: cenários para o desenvolvimento brasileiro. Núcleo de Estudos de População - Nepo. Campinas: Unicamp, 2007.

INSTITUTO BRASILEIRO DE GEOGRAFIA E ESTATÍSTICA. Censo 2010. IBGE, 2013.

INTERGOVERNMENTAL PANEL ON CLIMATE CHANGE (IPCC). 2007. Working Group II - Climate Change Impacts, Adaptation and Vulnerability. United Kingdom: Crown.

INTERGOVERNMENTAL PANEL ON CLIMATE CHANGE (IPCC). 2013. Summary for Policymakers. In: STOCKER, T. F. et al. Climate Change 2013: the physical science basis. Contribution of Working Group I to the Fifth Assessment Report of the Intergovernmental Panel on Climate Change. Cambridge, United Kingdom and New York, NY, USA: Cambridge University Press.

KASPERSON, J. X. et al. Vulnerability to Global Environmental Change. In: KASPERSON, J.; KASPERSON, R. The social contours of risk: publics, risk communication and the social amplification of risk. London: Earthscan, 2005. p. $245-85$

LEISEROWITZ, A. Public Opinion, Perception, and Understanding of Global Climate Change. Human Development Report 2007/2008 - Fighting climate change: Human solidarity in a divided world. Human Development Report Office, 2007/2008. Disponível em: <https://hdr.undp.org/en/reports/global/hdr2007-2008/papers/leiserowitz_ anthony6.pdf>. Acesso em: 24 jan. 2013.

LEISEROWITZ, A. et al. Public support for climate and energy policies in September, 2012. Yale University and George Mason University. New Haven, CT: Yale Project on Climate Change Communication.

LITRE, G.; BURSZTYN, M. Percepções e adaptação aos riscos climáticos e socioeconômicos na pecuária familiar do bioma pampa. Ambiente \& Sociedade, São Paulo. v. XVIII, n. 3, p. 55-80. jul.-set. Disponível em: <http://dx.doi. org/10.1590/1809-4422ASOC668V1832015>. 2015.

LOMBARDO, M. A. Ilha de Calor nas Metrópoles: exemplo de São Paulo. São Paulo: Hucited, 1985.

MARENGO, J. A. et al. “A seca e a crise hídrica de 2014-2015 em São Paulo." Revista USP, v. 106, p. 31-44, 2015.

NOBRE, C. A. et al. Some Characteristics and Impacts of the Drought and Water Crisis in Southeastern Brazil during 2014 and 2015. Journal of Water Resource and Protection, v. 8, p. 252-262, 2016. Disponível em: <http:// dx.doi.org/10.4236/jwarp.2016.82022>.

ORESKES, N. "The scientific consensus on climate change: how do we know we're not wrong?" In: Di MENTO, J. F. C.; DOUGHMAN, P. (Ed.). Climate Change: what it means for us, our children, and our grandchildren. MIT Press, p. 65-99, 2007.

PELLING, M.; HIGH, C. “Understanding Adaptation: what can social capital offer assessments of adaptive capacity?” Global Environmental Change, v. 15, p. 308-19, 2005.

RENN, O. The social amplification/attenuation of risk framework: application to climate change. Wires Climate Change, v. 2, p. 144-169, 2011.

RIBEIRO, W. C. Geografia política e gestão internacional dos recursos naturais. Estudos Avançados, v. 24, n. 68, p. 69-80, São Paulo, 2010. Disponível em: <http://dx.doi.org/10.1590/S0103-40142010000100008>.

SETZER, J.; MACEDO, L. V.; REI, F. Combining local and transnational action in adaptation of climate policies in the city of São Paulo. In: JOHNSON, C. et al. The urban climate challenge: rethinking the role of cities in the global climate regime, p. 101-118, 2015.

TORRES, R. R. Qual é o conhecimento disponível hoje e quais informações ainda faltam para São Paulo. Dezembro/2016. In: DI GIULIO, G. M. et al. Relatório Técnico-Científico Workshop Mudanças climáticas e o processo decisório na megacidade de São Paulo: análise das discussões promovidas, 2016-2017.

UITTENBROEK, C. J. et al. Political commitment in organising municipal responses to climate adaptation: the dedicated approach versus the mainstreaming approach. Environmental Politics, v. 26, n. 6, p. 1043-1063, 2014. 
VIOLA, E.; FRANCHINI, M. Climate politics in Brazil: public awareness, social transformations and emissions reduction. In: BAILEY, I.; COMPSTON, H. Feeling the heat: the politics of climate policy in rapidly industrializing countries. Hampshire: Palgrave, p. 175-201, 2012.

WEBER, E. U. What shape perceptions of climate change? Wires Climate Change, v.1, p. 332-342, 2010.

WISE, R. M. et al. Reconceptualising adaptation to climate change as part of pathways of change and response. Global Environmental Change, v. 28, p. 325-336, 2014.

WISNIK, G. A virada civilizatória de Haddad. Disponível em: <http://tools.folha.com.br/ print?site=emcimadahora\&url=http://www1.folha.uol.com.br/opiniao/2014/09/1521429-guilherme-wisnik-aagenda-de-haddad-para-o-futuro.shtml>. Acesso em: 20 out. 2014. 